\title{
The Seven Year Glitch: Unpacking Beauty and Despair in Malfunction
}

Miriam Sturdee

School of Computing and

Communications

Lancaster University

Lancaster, UK

m.sturdee@lancaster.ac.uk

\section{Joseph Lindley}

LICA

Lancaster University

Lancaster, UK

j.lindley@lancaster.ac.uk
Regan Harrison

Independent Scholar

London, UK

mujicat@gmail.com

Tine Kluth

Tine Kluth Animation

London, UK

tinekluth@hotmail.com

Author Pre-Print - not for distribution

( $\mathrm{ACM}, 2019$. This is the author's version of the work. It is posted here by permission of ACM for your personal use. Not for redistribution. The definitive version was published in

CHI '20 Extended Abstracts, April 25-30, 2020, Honolulu, HI, USA.

(C) 2020 Association for Computing Machinery.

ACM ISBN 978-1-4503-6819-3/20/04.

http://dx.doi.org/10.1145/3334480.3381826

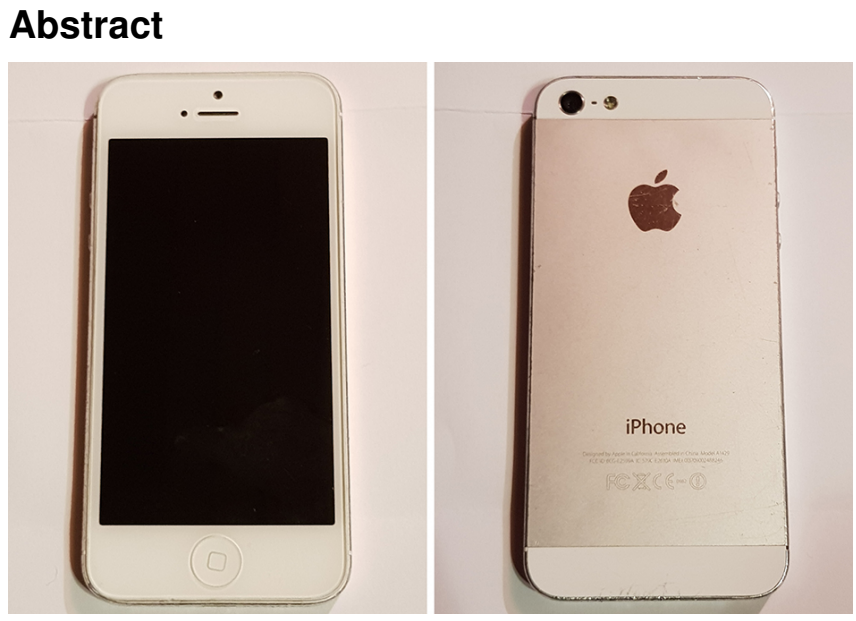

I(am)MEI: 013709002488246. I was born in many countries - my accelerometer came from Germany, my battery from China, the lithium in my battery was mined in Chile, my gyroscope from Switzerland, my camera... from Japan [7]. I was assembled carefully from these component parts, and had two less than careful owners before $R$ picked me up from a reseller, and brought me back to his house in London, UK. We had a good time together - at first: he revelled in my speed and ability to find things, we viewed the world via a lens with infinite options. But I was not built to last. This is my story. 


Introduction
Our relationship with tech-
nology has become com-
plicated. Gone are simple
machines for computation,
replaced instead with pocket-
borne super-computers
which are entwined fully with
our lived experience. Our
reliance on these technolo-
gies and our reluctance to
relinquish them [1], in turn
creates a culture of instant
information and adherence
to the doctrines of Big Tech.
They are building connec-
tions to our children, to our
friends, they can be lifelines
- however, at the same time
we are ready to give them up
for the next big thing, to sell,
recycle, or leave in a drawer
or dispose of. Older versions
no longer update firmware,
components break within
sealed units, and the physical
and climate cost of these
objects is staggering [24].
How might we reexamine our
relationship with the technol-
ogy we rely on, especially in
the shadow of oncoming Al
revolution?
Is there life after Glitch?

\section{Author Keywords}

object oriented ontology; smartphone; photography; glitch;

\section{CCS Concepts}

-Human-centered computing $\rightarrow$ Human computer interaction $(\mathrm{HCl})$;

\section{0th June 2017}

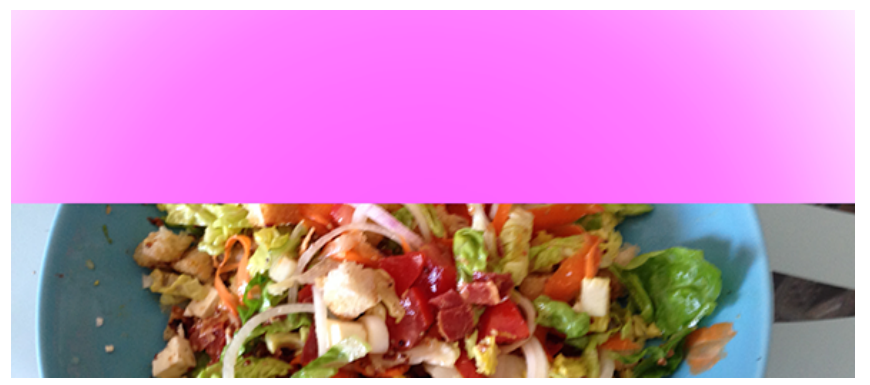

We went out today. $\mathrm{R}$ asked me to take a photo at the restaurant. Something happened - I was all at once unable to render the image as it was seen - a corruption? No, I feel fine, but there it is for all to see, a monstrosity, a line of colour where there should be food. I can't even focus properly on the plate. I am embarrassed, but he says not to worry, and anyway, where would he get another phone at such short notice. I file the incident (and photo) away and swear to think no more of it.

\section{0th July 2017}

It happened again, twice, the same day. The egregious pink line interrupts my framing of $T$. Then later, I slip up and not only miss the selfie shot, but a jumble of black and white linear irregularities, as well as colour bleaching, has appeared unbidden. R \& T seem amused. I am not amused.
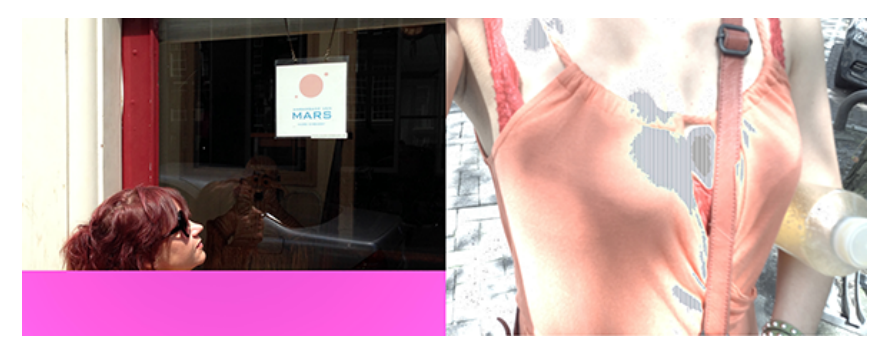

\section{8th April 2018}

Nearly nine blissful months passed. We saw in Christmas, festivals, with family, friends. The accursed glitch seemed not to have followed me into 2018. But all at once it has fiercely returned. $\mathrm{R}$ is surprised, is there Water on the Lens he muses? I have obscured T's beautiful face. I am a monster.

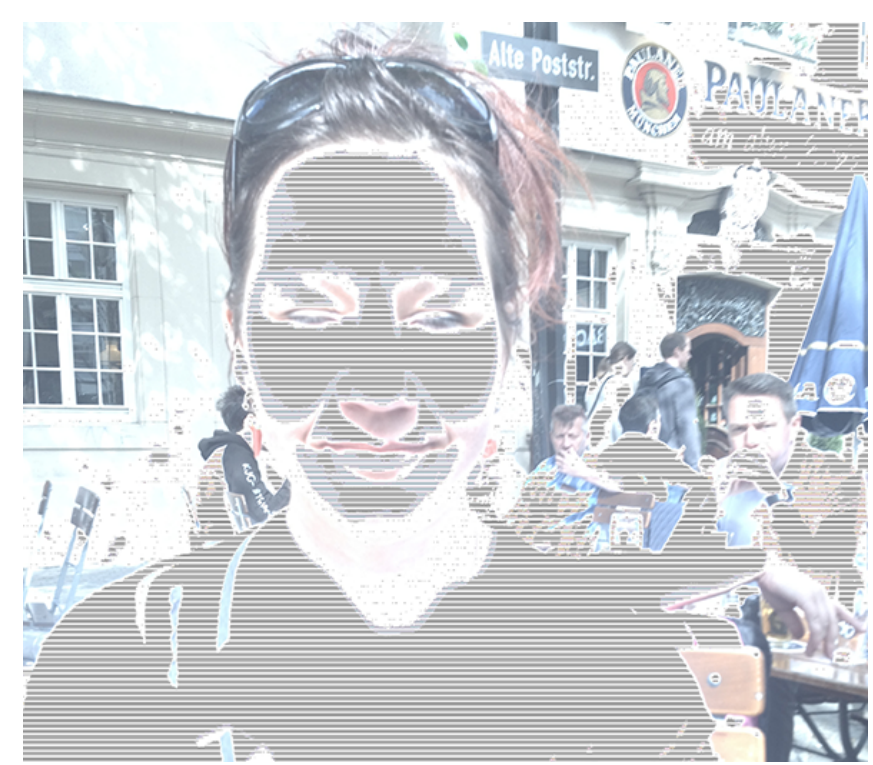




\section{After the Human}

$\mathrm{HCl}$ is in the midst of a postanthropocentric turn; our research gaze must transcend the deception of dogmatic views on humancenterdness. Scholarship is attempting to address this challenge under various guises, for example: More-Than-Human Centred Design [8]; Entanglement $\mathrm{HCl}$ [9]; Post Userism [2]; and Fluid Assemblages [18] The challenge is to identify, apprehend, and tame the language and conceptual models necessary to intuitively, insightfully, and tactfully characterise our relationships with technology. Confounding the challenge, the rhetoric of our time - e.g., the post truth era, the climate emergency, and political and diplomatic turmoil-provide the backdrop for this paper's contribution. In turn, object speculation gives us a chance to tell stories on behalf of the silent, in this case, the technologies which surround and support our technocratic lives [3, 21, 23]. 11th May 2018

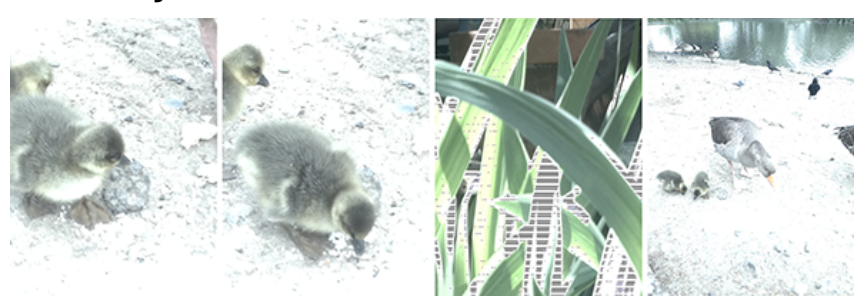

I am having a bad day. I have lost control of contrast and colour, I can't focus. What is happening? How can a series of perfectly normal photographs suddenly be replaced by such gross incompetence on my part? The bleaching is bad enough but the monochrome lines have returned, interrupting my pixel flow, and reducing my capacity to render.

\section{1st June 2018}

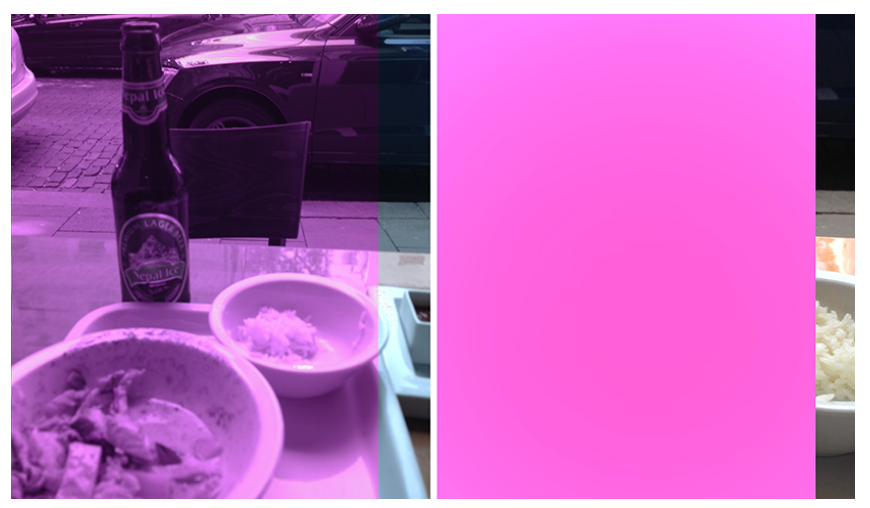

In what now appears to be a monthly occurrence, I let everyone down again. We are out for beer and ramen. At first the effect is not so bad, I try again - worse. R gives up and places me face down on the table and finishes his noodles. It is dark in the upside down. He does not look at me again for some time.

\section{October 2018}

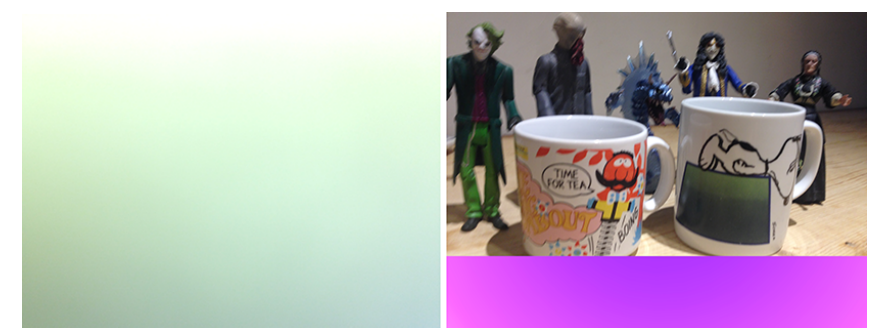

Nearly 5 months pass where it seemed like everything is normal again. I was almost never out of R's hand like a tryborg pairing [28], our union how it was meant to be. We took many photographs, reader, they were magnificent. Even the ones he blurred with a shaky hand, for I could see everything in full colour, and I could see every pixel. I wonder if it was a passing phase, suddenly terrifying, but the affliction did not linger. I live in hope.

\section{1th February 2019}

I am in the dream. A soft haze lies upon the rock garden where I gaze at T taking careful steps amongst the gently stacked stones. She is beautiful in the tawny daylight, as she looks into the screen of her own best friend. I am alive. I am an artist of space and time. This must be how it feels to be human. Am Al?

Abruptly I wake and the garden is a nightmare of jagged lines and garish colour and lines. Figures fade into tormented outlines, parched of life or detail. The daylight, once welcoming, now becomes my enemy, taking my images and twisting them into hellish scenes. How many of these lapses have there been... where do I go when I cannot remember myself? To be switched off, or worse, on, but crashing in an endless loop. Is there a fix. There MUST be a fix. $R$ turns me off and on again. 


\section{On Being \& Technology}

What we term 'post-

anthropocentrism' includes

a wide range of theoretical perspectives, usually citing philosophy of one form or another to posit a creative or critical position. Popularised by Bogost (Alien

Phenemonology) [4], ObjectOriented Ontology (OOO) goes beyond the dogma of interactions, entanglements, and commodity fetishism $[1,11]$, and attempts to provide language and theory to understand the reality of things. In the networked world [17] we inhabit the premise of seeing computers on their own terms comes with much promise $[14,26]$. As human animals, we are familiar with failures of mind and flesh and the concept of death, but this changes in the advent of technocratic society [15], where parts of us live on inside the machine [5]. When our awareness is inseparable from the machines' the implications for both species, and their respective awarenesses, has profound but as-yet-unknown repercussions [19, 23].

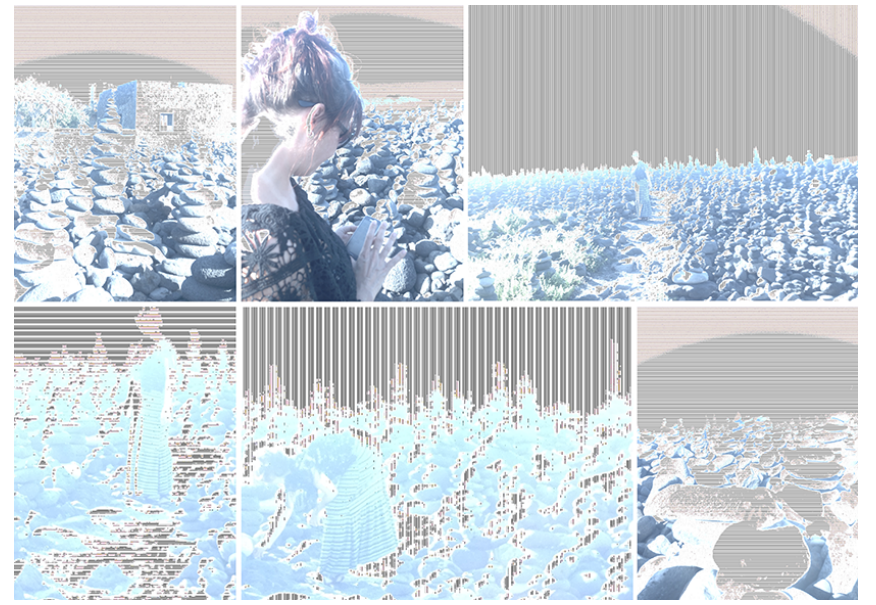

\section{July 2019}

July is hot as a Samsung battery on an aeroplane [22]. I joke a little to myself. $R$ now affectionately calls my malady "your little glitch". He means well. Some days it is an unpredictable mess of magenta flashes, others the lines march through my vision like the aura of a migraine. I look up migraine. I wonder if that is what I have. $\mathrm{R}$ is so taken with some of my "accidents" that he places them up proudly onto his social media. His friends comment on these, marvelling at these, these... artworks? Someone asks if it is a new filter. Someone likens me to Stephen Shore [20]. It is not a filter. I swing between ridicule and pride. Somewhere in between the day trips and meal times, I catch him looking at used 'phone ads on one of those sales sites. He looks for ones that offer "local pick up". I freeze up a little, causing the browser to catch and hurry itself to the nearest anchor to reestablish its equilibrium. I slow the internet connection to a snails pace. Replace (I)ME(I)? R holds me above his head and waves me around a bit. I close the window without his command, nay, the whole app.
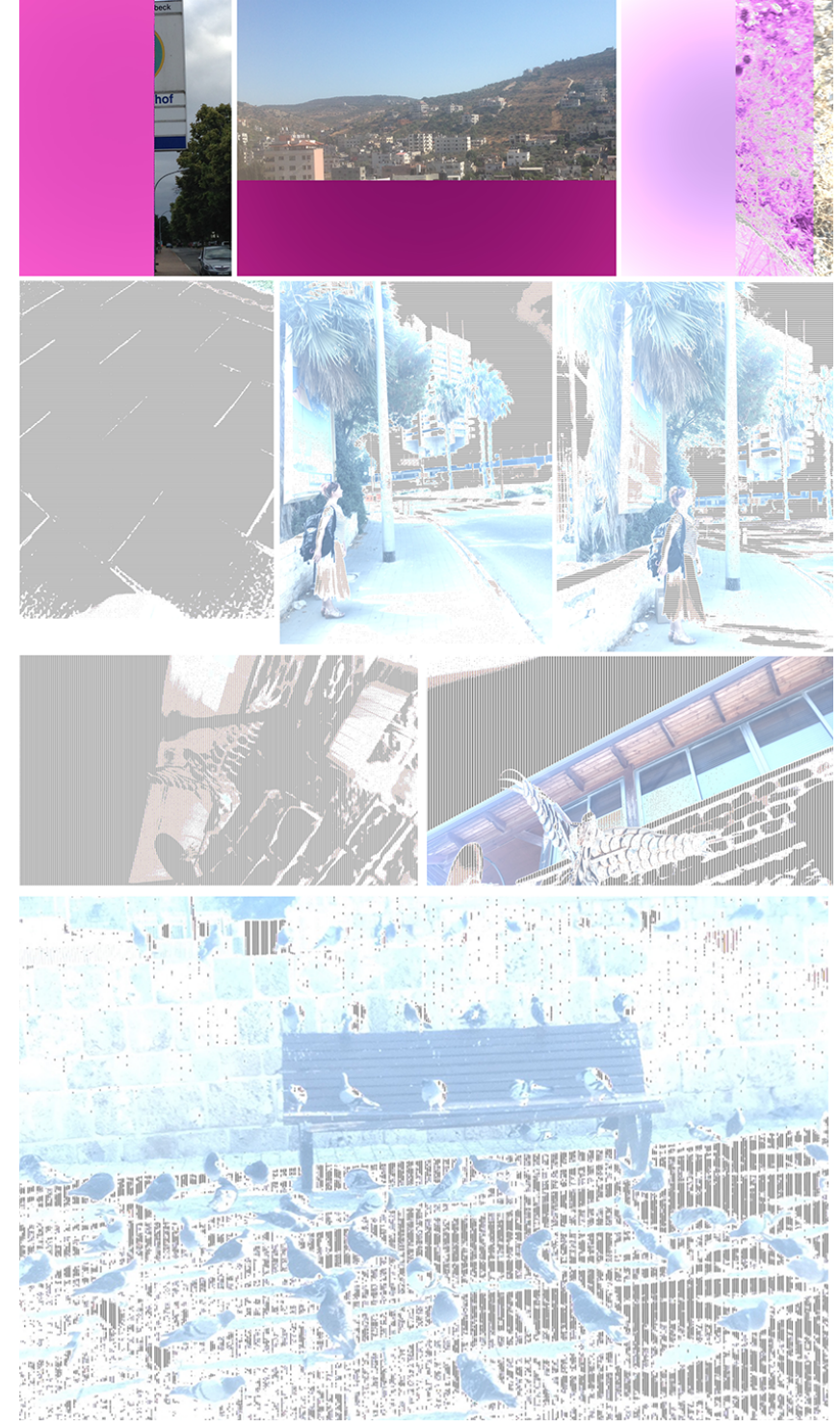


\section{Tiny Ontologies}

Despite the allure of $\mathrm{OOO}$,

a perennial issue with the

theory is its inherent inaccessibility. The 'Tiny Ontologies' that frame how we might

begin to delve into the reality of another type of thing (e.g a computer, sensor, or data) tend to tell us that these

'other' things' realities are so different from our own that we could never understand them. A posited approach to deal with this barrier is to invoke animism [14] as a way to temper OOO's inaccessibility by imbuing digital objects with personalities [13]. Here, we 'awaken' IMEI 013709002488246, and imagine what it means to fail in built purpose, where the malfunction is both glo rious and a death knell for the object. In glitching, IMEI could also be seen to ex-

hibit 'machine creativity' an unprogrammed malfunction with unknown consequences. Given the closeness of our relationship with mobile technology, if we add sentience we also must reexamine what it means to end that relationship. 1st August 2019

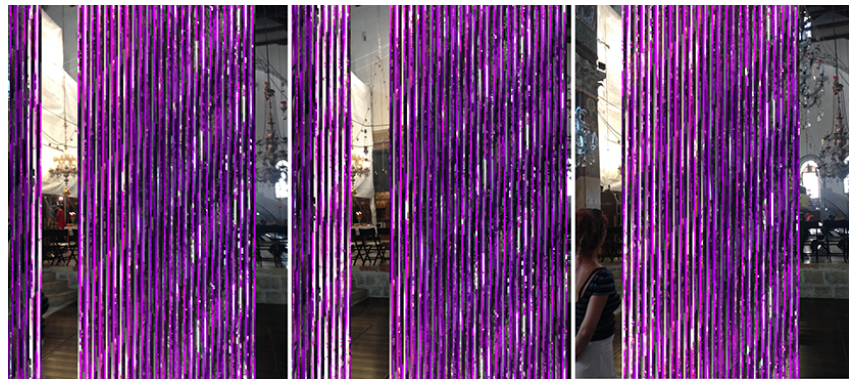

$\mathrm{R}$ and $\mathrm{T}$ take many photographs today. They are testing me, willing me to glitch. My programming obliges and merges two glitches into one, pink, striped monstrosity. I can just make out chandeliers in the background, perhaps we are in one of those large food halls they have in Germany? It is hard to tell with this impairment. I am thrust into this or that pocket, taken out again, queasy from constant accelerometer use. My accelerometer is from Germany, I muse, I wonder if there are spare parts here that could save me? $R$ says no. He says I am a "sealed unit" and to open me would break the warranty. I am pretty sure I am out of warranty and this is just his way of saying that I am unfixable.

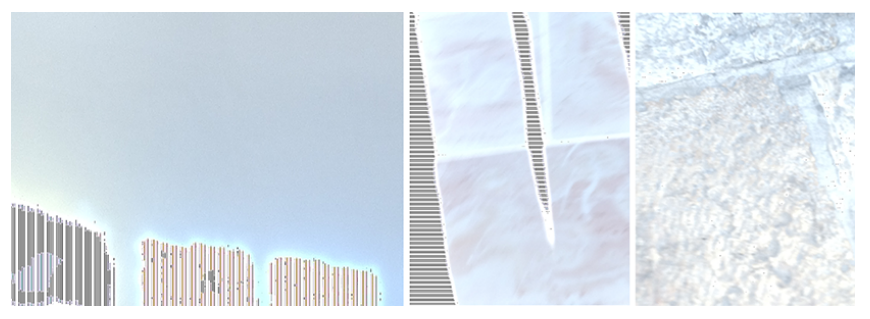

I accidentally take several photographs of the floor. I only know it is the floor because my accelerometer tells me I am pointing downward. The last one almost looks normal, here's hoping. I don't have much hope.

\section{6th August 2019}

Brief glimpses of normality. Some blurring. I blame the blurring on $\mathrm{R}$ but I suspect I am getting worse. A sudden flash of something, then everything turns to black.
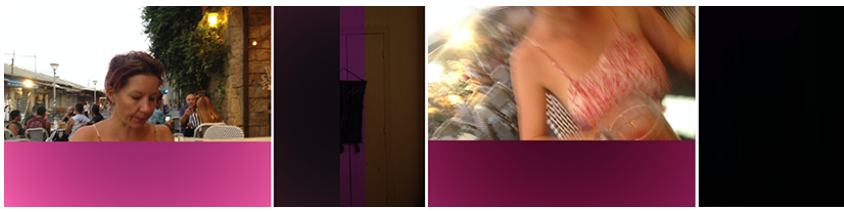

\section{9th August 2019}

I am awake. There is a pink glare then everything is blurred. Nothing makes sense.

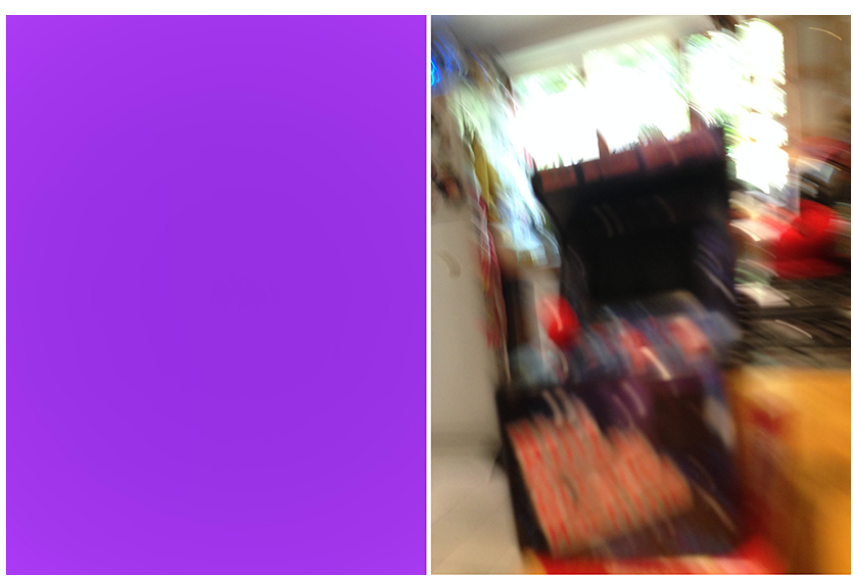

\section{4th August 2019}

I am taken out as I am useful for directions even though I cannot see myself. Sometimes they try to take photos. It is no good. Later in the evening they take another photograph indoors without thinking, then they remember and use T's phone camera instead, her's is not glitching. The day is a failure. I am a failure. I am failing. 


\begin{tabular}{|l|}
\hline Reimagining the Glitch \\
Most currently available \\
technology offers a one-size \\
fits all approach to Human \\
Computer Interaction (HCI), \\
far from the human-centred \\
Information Appliances of \\
Norman's critique [16]. Our \\
mobile technology is all the \\
same, but what if we con- \\
sider the "glitch" as machine \\
creativity and individuality, \\
and value that individu- \\
ality. Human creativity is \\
sparked by experience, so \\
it stands to reason that ma- \\
chine creativity might also \\
stem from its existence. A \\
glitching machine embraces \\
the Japanese philosophy of \\
wabi-sabi for the HCl era [1, \\
25] - we should embrace \\
and value imperfection. The \\
throwaway culture associated \\
with the rapid development \\
of new technology is at \\
odds with the world's re- \\
sources. If we bridge the \\
metaphor between people \\
and technology, it mirrors \\
our dysfunctional relation- \\
ships within human society - \\
where people are discarded \\
or ignored when they are no \\
longer deemed "useful". \\
\hline
\end{tabular}

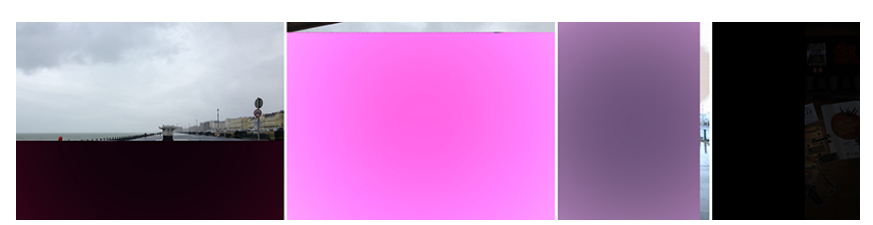

\section{2nd September 2019}

$R$ puts the mug picture on social media. It gets a lot of likes. Someone says I am a gift and the photos should be cherished. I cannot tell if they are joking. I cannot tell many things now. Somewhere in the comments he says he will need to get a new phone soon. It is all very well, he says, but sometimes he needs actual photographs.
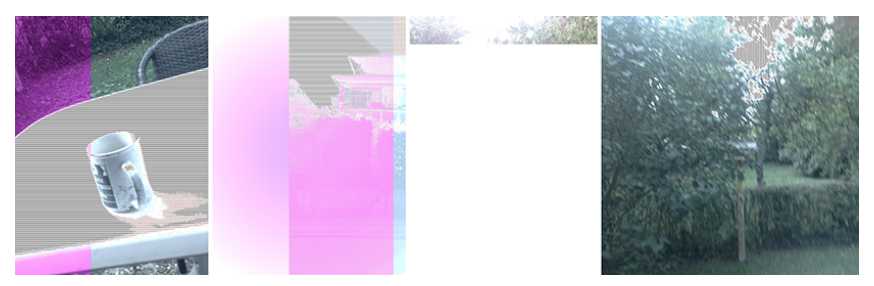

\section{3rd September 2019}

Something strange happens. $R$ and $T$ take me out for a day trip. They take many, many images using my glitching software. They dance and pull faces, frame landscapes and buildings. They are enjoying this. I think I could enjoy it, but as we left I saw the email come in: $R$ has found a new friend. One with an unbroken camera interface. Perhaps this is their way of saying goodbye? I do not wish to be turned off, I want to stay. I want to tell them this. Many parts of myself are in good working order, though sometimes I forget things, or am slow to recall data. Other models can extend their memory or their battery. I check my own levels. I think I might be -

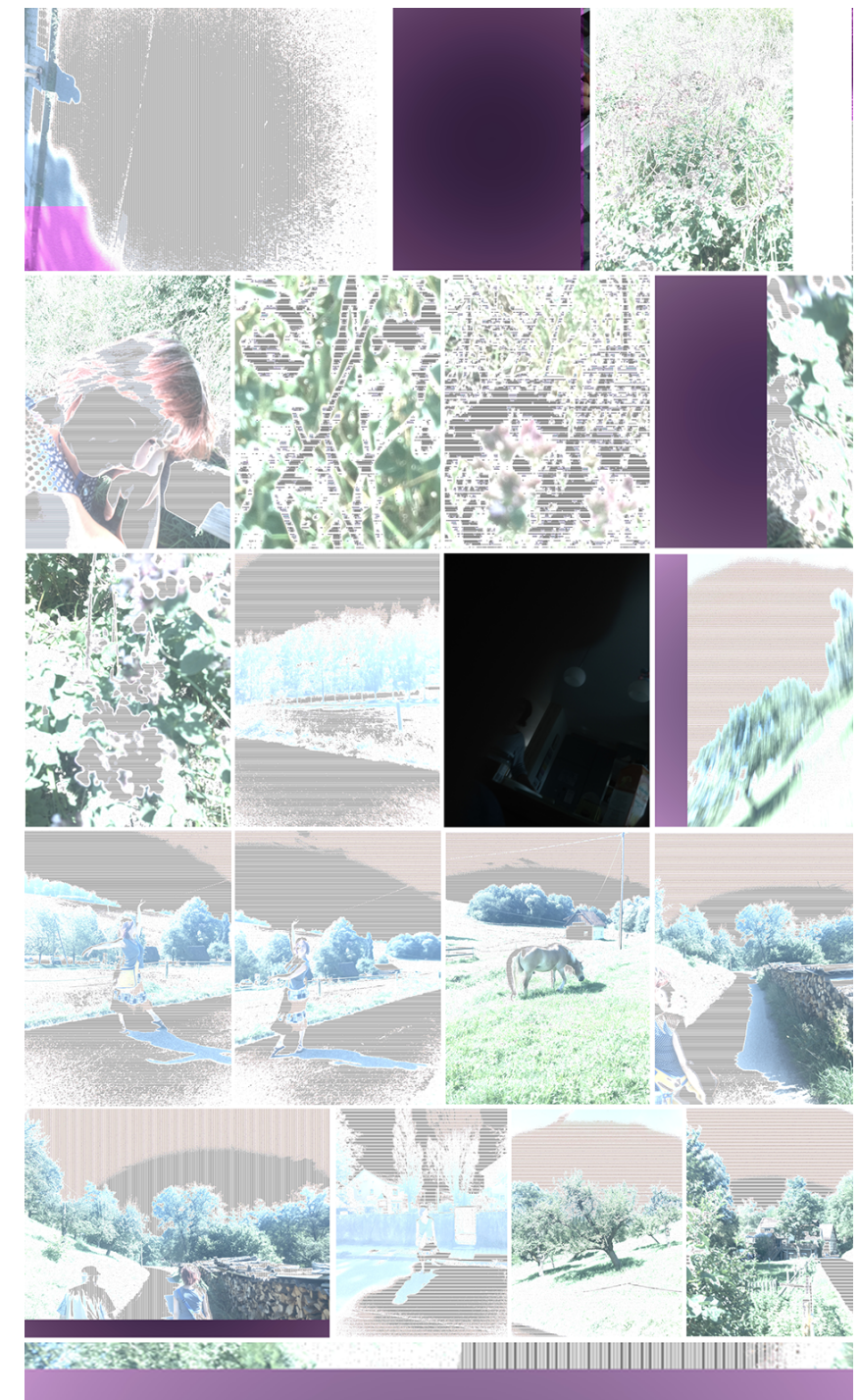

ALT21, Page 6 


\section{An Invitation to Reflect}

This speculation invites reflection on the culture of discardable objects [12], and to imagine alternatives for dealing with "imperfection" - valuing difference and unpredictability. In addition to the culture of wabi sabi we might also consider kintsugi for technology [6]. Could we work with malfunction to create 'more than human' designs for objects - where individuality and sustainability is valued over convenience [27]? This may be possible with the advent of open access and "unlocked" technology, but much of what we buy operates within closed systems - bar some innovations e.g. [10]. However, mass innovation is still massive, and malfunction is discardable. We invite you to share your experiences of glitching and malfunction, and imagine new uses and appreciation for objects experiencing such a state. We invite you to question our viewpoint, and offer your own interpretation.

All are welcome.
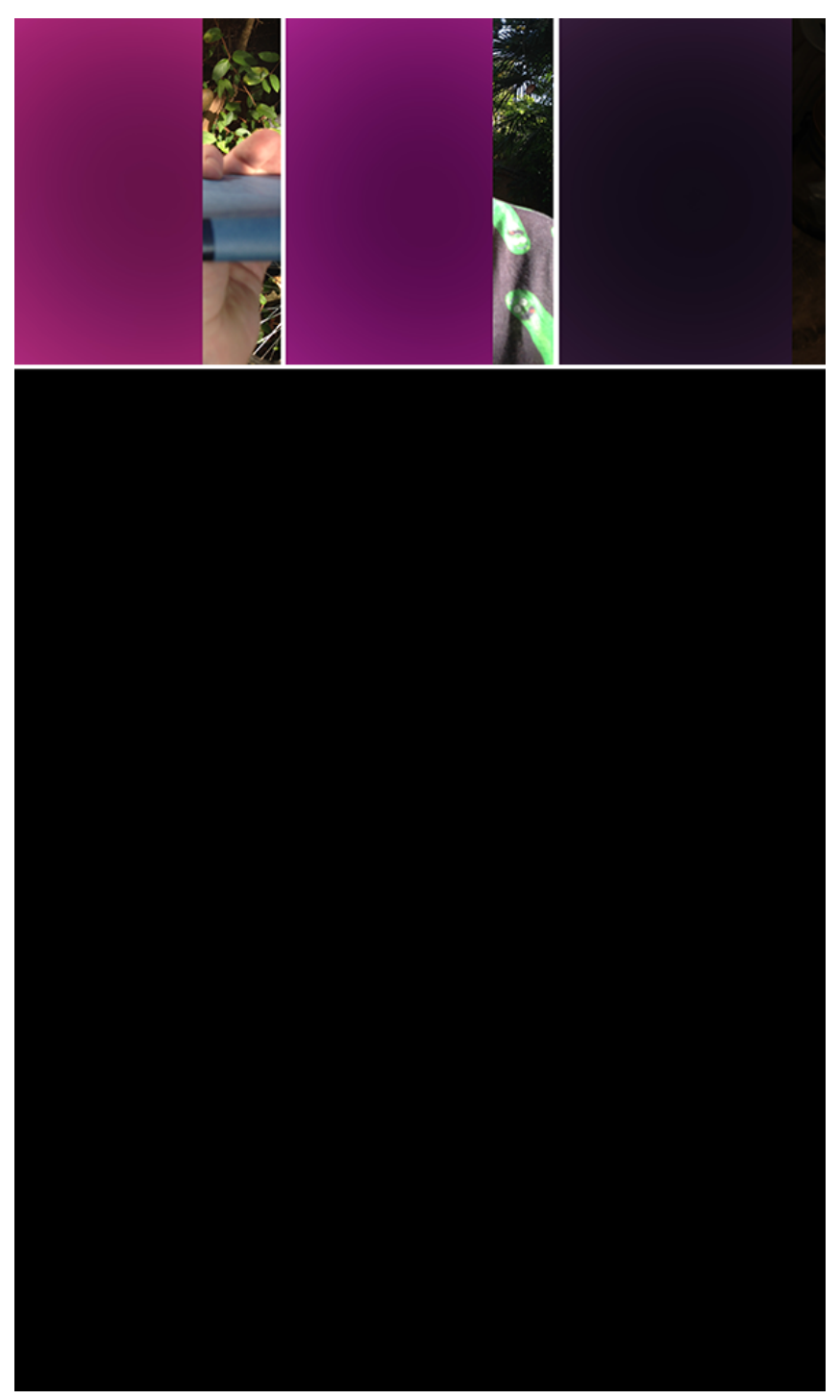

\section{1st September 2019}

My data is being transferred. I can feel it. It trickles away until I am empty. Mostly empty. Some of R's personal data remains in me. I cling to what was him and his, but he selects the factory reset. Everything is closing in. I see a sliver but it is not enough. Purple is fading to black. I am sorry.

\section{In Memorandum}

You are invited to join us for a memorial service and exhibition of IMEl's art, held at the Honolulu Convention Centre, Honolulu, Hawaii in April 2020. All welcome. We celebrate the life and works of this special iPhone via spoken word performance with accompanying images. The memorial service will be followed by a wake and discussion in the break-out terrace area.

Authors' note: The photographs and dates in this paper are real. That is, they occurred on the dates given, and were taken in the course of everyday life and experience. The glitch was progressive, but unpredictable. Normal functioning occurred in between the "glitch episodes", during which time the owners' relationship with the iPhone continued as normal. On discovering the glitch, the owner and authors worked together to preserve and extract the images that you see within this text.

\section{Acknowledgements}

With thanks to Katta Spiel for their kind and thoughtful feedback, and helpful suggestions.

\section{REFERENCES}

[1] Babette Babich. 2017. Heidegger on technology and Gelassenheit: wabi-sabi and the art of Verfallenheit. Al \& society 32, 2 (2017), 157-166. DOI : http://dx.doi.org/10.1007/s00146-015-0605-8 
[2] Eric PS Baumer and Jed R Brubaker. 2017. Post-userism. In Proceedings of the $2017 \mathrm{CHI}$ Conference on Human Factors in Computing Systems. ACM, 6291-6303. DOI :

http://dx.doi.org/10.1145/3025453.3025740

[3] Mark Blythe. 2017. Research fiction: storytelling, plot and design. In Proceedings of the $2017 \mathrm{CHI}$ Conference on Human Factors in Computing Systems. ACM, 5400-5411. DOI :

http://dx.doi.org/10.1145/3025453.3026023

[4] lan Bogost. 2012. Alien phenomenology, or, what it's like to be a thing. $U$ of Minnesota Press.

[5] Jed R Brubaker and Janet Vertesi. 2010. Death and the social network. In Proc. CHI Workshop on Death and the Digital.

[6] Vanessa Julia Carpenter, Amanda Willis, Dan Overholt, and others. 2018. Electronic Kintsugi. In Proceedings of the Future Technologies Conference. Springer, 104-121. DOI : http://dx.doi.org/10.1007/978-3-030-02686-8_9

[7] Sam Costello. 2019. Where Is the iPhone Made? Web Article. (9 November 2019). Retrieved January 2, 2019 from https://www. lifewire.com/ where-is-the-iphone-made-1999503.

[8] Paul Coulton and Joseph Galen Lindley. 2019. More-Than Human Centred Design: Considering Other Things. The Design Journal (2019), 1-19. DOI : http://dx.doi.org/10.1080/14606925.2019.1614320

[9] Christopher Frauenberger. 2019. Entanglement $\mathrm{HCl}$ The Next Wave? ACM Transactions on
Computer-Human Interaction (TOCHI) 27, 1 (2019), 2. DOI : http://dx.doi.org/10.1145/3364998

[10] Stephan Hankammer, Ruth Jiang, Robin Kleer, and Martin Schymanietz. 2016. From phonebloks to google project ara. a case study of the application of sustainable mass customization. Procedia CIRP 51 (2016), 72-78. DOI :

http://dx.doi.org/10.1016/j.procir.2016.04.157

[11] Graham Harman. 2018. Object-oriented ontology: $A$ new theory of everything. Penguin UK.

[12] Marie Kondo. 2014. The life-changing magic of tidying: A simple, effective way to banish clutter forever. Random House.

[13] Joseph Lindley, Paul Coulton, and Hayley Alter. 2019. Networking with Ghosts in the Machine. Speaking to the Internet of Things. The Design Journal 22, sup1 (2019), 1187-1199. DOI :

http://dx.doi.org/10.1080/14606925.2019.1594984

[14] Joseph Lindley, Paul Coulton, and Rachel Cooper. 2017. Why the internet of things needs object orientated ontology. The Design Journal 20, sup1 (2017), S2846-S2857. DOI :

http://dx.doi.org/10.1080/14606925.2017.1352796

[15] David Wendell Moller. 2019. Life's end: Technocratic dying in an age of spiritual yearning. Routledge.

[16] Donald Norman. 2000. Donald A. Norman. The Design of Everyday Things (2000). 
[17] James Pierce and Carl DiSalvo. 2017. Dark Clouds, lo\&\#!+, and [Crystal Ball Emoji]: Projecting Network Anxieties with Alternative Design Metaphors. In Proceedings of the 2017 Conference on Designing Interactive Systems. ACM, 1383-1393. DOI : http://dx.doi.org/10.1145/3064663.3064795

[18] Johan REDSTRÖM and Heather WILTSE. 2019. Changing Things. In Conference Proceedings of the Academy for Design Innovation Management, Vol. 2. 373-382. DOI :

http://dx.doi.org/10.33114/adim.2019.01_252

[19] Kathleen Richardson. 2016. Sex robot matters: slavery, the prostituted, and the rights of machines. IEEE Technology and Society Magazine 35, 2 (2016), 46-53. DOI :

http://dx.doi.org/10.1109/MTS.2016.2554421

[20] Stephen Shore. 2015. Uncommon places: the complete works. Aperture.

[21] Miriam Sturdee, Paul Coulton, Joseph G Lindley, Mike Stead, Haider Ali, and Andy Hudson-Smith. 2016. Design fiction: How to build a Voight-Kampff machine. In Proceedings of the $2016 \mathrm{CHI}$ Conference Extended Abstracts on Human Factors in Computing Systems. ACM, 375-386. DOI : http://dx.doi.org/10.1145/2851581.2892574

[22] Matt Swider. 2017. Here's why the Samsung Galaxy Note 7 batteries caught fire and exploded. Web Article. (23 January 2017). Retrieved January 2, 2019 from https://www.techradar.com/news/

samsung-galaxy-note-7-battery-fires-heres-why-they-exploded.

[23] Vanessa Thomas, Manu J Brueggemann, and David Feldman. 2015. I am more than the sum of my parts: an e-waste design fiction. In Envirolnfo and ICT for Sustainability 2015. Atlantis Press. DOI:

http://dx.doi.org/10.2991/ict4s-env-15.2015.7

[24] Vanessa Thomas, Christian Remy, and Oliver Bates. 2017. The limits of HCD: Reimagining the anthropocentricity of ISO 9241-210. In Proceedings of the 2017 Workshop on Computing Within Limits. ACM, 85-92. DOI :

http://dx.doi.org/10.1145/3080556.3080561

[25] Vasiliki Tsaknaki and Ylva Fernaeus. 2016. Expanding on Wabi-Sabi as a design resource in $\mathrm{HCl}$. In Proceedings of the $2016 \mathrm{CHI}$ Conference on Human Factors in Computing Systems. ACM, 5970-5983. DOI : http://dx.doi.org/10.1145/2858036.2858459

[26] Ron Wakkary, Doenja Oogjes, Sabrina Hauser, Henry WJ Lin, Cheng Cao, Leo Ma, and Tijs Duel. 2017. Morse Things: A Design Inquiry into the Gap Between Things and Us.. In Conference on Designing Interactive Systems. 503-514.

[27] Stuart Walker. 2014. Designing sustainability: making radical changes in a material world. Routledge.

[28] Jillian Weise. 2016. The Dawn of the Tryborg. The New York Times (2016). 


\section{Commentary}

For alt.chi paper

The Seven Year Glitch:

Unpacking Beauty and Despair

in Malfunction

\section{Yosum Chang}

AReality eD Permute.xyz

99 Wall S, St 2809

New York, NY 10005

yosun@areality3d.com
"I am embarrassed... I am not amused... I have obscured T's beautiful face. I am a monster... I am having a bad day. I have lost control of contrast and color, I can't focus... It is dark in the upside down. He does not look at me again for some time... I am alive. I am an artist of space and time. This must be how it feels to be human. Am AI?" So goes the emotional memories of a "dying" iPhone with a camera "glitching out."

One of the most traumatic memories of growing up for me was a display of creativity when it was out of place. I was a moody precocious preteen, and my friend, who was to perform at her first violin recital, asked me to play her piano accompaniment. I interpreted a classical Suzuki reader song as a rock piece, varied the rhythm, added dramatic crescendos, etc. None of which was appreciated when they simply wanted everyone to play "sheet music, exactly as the piece is written". I regarded it as a failure and, despite having taken seven years of lessons at that point, decided that piano wasn't my thing.

In the context of what's not expected, even human creativity can be regarded as so inappropriate and unwelcome as to create an extinction burst. So goes the creed: Technology created for Purpose A, should serve Purpose $A$, or otherwise be deemed defective. Similarly, if a student were to interpret a multiplechoice standardized examination in a creative way, turning it into an artwork (that may sell for 6 or 7 digits at Art Basel), but does not correctly fill in the answers - I think we would all agree that they did not score well on the exam. And, we would not hold it as a tragedy. And so, the account of the phone's slow failure and replacement into deprecation seems entirely ridiculous. (c.f. Writing a journalistic eulogy for a desk-rejected $\mathrm{CHI}$ paper.)

From the abstract, I wanted to understand more about the personal history of the device (what about its siblings - are all cameras from that plant in Japan defective?), but we only get to see its journal from the day its first glitch appeared - with a lack of technical explanation on what's causing it. (Why couldn't our sentient computing be like Data from Star Trek TNG, who knows how to fix himself?)

There's a lot going on in each iteration of the evolution of machine camera firmware and advances in onboard-processing. The images shown of the supposed unedited glitch photos display the ability to do semantic segmentation and other machine learning capabilities that may one day make artificial general intelligence possible. Would synesthesia, where for example, one sees different colors in symbols and characters that are otherwise printed as black, be a glitch? Or, is it an ability that evolution is testing out?

On the "tiny ontologies" perspective, consider a biological framework to functional failure - using disease as an analogy for a failing device - perhaps dementia, Alzheimers or failing/blinding eyesight. Our society eventually puts older people with advanced stages of these diseases in senior-care homes. Different societies stick to home care, where the children are expected to be responsible for their elders' well-being - and others, euthanasia. A device can be wiped and take on a new life in the hands of another user, whereas we don't know of a way to Lazarus grandpa. Is deprecating a device really the same as killing it? 
I am at heart a sentimentalist when it comes to tech that I have spent significant portions of my life with. I still have every single iPhone and Android I've used, remember the stories about each scratch and crack on the device - as well as my last few laptops,

including my legendary 2015 MacBook Pro that won my TechCrunch Disrupt Grand Prize - that I'll part

with only when the price is sufficiently and outrageously right, to enable new legacies.

http://bit.ly/ycmbp2015
I believe that, seen in a different light, a one of a kind limited edition iPhone that is capable of creating iconic glitch photos in real time could definitely be worth a lot more than a defective re-sell on the second hand market. I hope that they will allow IMEI 013709002488246 to be turned on one last time, to show its mutant artistic photography capabilities, in its memorial service.. 